\title{
Differential Expression of Oxidative Stress and Inflammation Related Genes in Peripheral Blood Mononuclear Cells in Response to a Low-Calorie Diet: A Nutrigenomics Study
}

\author{
Ana B. Crujeiras,,$^{1, \star}$ Dolores Parra, ${ }^{1, \star}$ Fermín I. Milagro, ${ }^{1}$ Estibaliz Goyenechea, ${ }^{1}$ Eider Larrarte,${ }^{2}$ \\ Javier Margareto, ${ }^{2}$ and J. Alfredo Martínez ${ }^{1}$
}

\begin{abstract}
Nutrigenomics is a new application of omics technologies in nutritional science. Nutrigenomics aims to identify molecular markers of diet-related diseases and mechanisms of interindividual variability in response to food. The aim of this study was to evaluate peripheral blood mononuclear cells (PBMC) as a model system and readily available source of RNA to discern gene expression signatures in relation to personalized therapy of obesity. PBMC were collected from obese men before and after an 8-week low-calorie diet (LCD) to lose weight. Changes in gene expression before and after the LCD were initially screened using a DNA-microarray platform and validated by qRT-PCR. Global gene expression analysis identified 385 differentially expressed transcripts after the LCD. Further analyses showed a decrease in some specific oxidative stress and inflammation genes. Interestingly, expression of these genes was directly related to body weight, while a lower IL8 gene expression was associated with higher fat mass decrease. Collectively, these observations suggest that PBMCs are a suitable RNA source and model system to perform nutrigenomics studies related to obesity and development of personalized dietary treatments. IL8 gene expression warrant further research as a putative novel biomarker of changes in body fat percentage in response to an LCD.
\end{abstract}

\section{Introduction}

U NDERSTANDING THE MOLECULAR BASIS involved in obesity and weight homeostasis is a crucial first step in developing therapeutic strategies against excess in body weight gain (Sun, 2007; Viguerie et al., 2005a). Based on this, the study of gene expression at the level of mRNA in response to changing conditions, such as in nutritional intervention studies (Kussmann et al., 2006), is being carried out by transcriptomics, mainly using arrays (Heidecker and Hare, 2007; Moreno-Aliaga et al., 2001). This new field, known as nutrigenomics, attempts to elucidate the impact of diet on gene expression, whose long-term aim is personalized nutrition for health maintenance and disease prevention (Kaput, 2008; Mariman, 2006; Vakili and Caudill, 2007).

In this context, most gene expression studies in human obesity are often focused on adipocytes, mainly on biopsed subcutaneous adipose tissue (Hernandez-Morante et al., 2008; Marrades et al., 2006; Viguerie et al., 2005a). Analysis of visceral adipose tissue is basically restricted to morbid pa- tients, whose tissue samples can be easily obtained during surgery (Baranova et al., 2005). However, nutrigenomics studies in humans have remained clearly insufficient to date because it is difficult to obtain biopsies from every volunteer involved in a nutritional study due to the invasive sample collection procedure (Kussmann et al., 2006).

Molecular mechanisms underlying several human diseases have been investigated by gene expression analysis of peripheral blood mononuclear cells (PBMC) as surrogates for predicting potential effects in tissues that are not easily accessible (Eady et al., 2005). These cells have been proposed as a useful tool to better understand multiple sclerosis related pathways (Achiron and Gurevich, 2006), the pathophysiology of Alzheimer's disease (Maes et al., 2006), hepatic diseases (Chiappini et al., 2006; Patalay et al., 2005), oncology (DePrimo et al., 2003; Twine et al., 2003), and cardiovascular research (Horwitz et al., 2004). Also, peripheral blood mononuclear cells (PBMC) were suggested as a surrogate tissue to muscle biopsies to study mitochondrial dysfunction (Abu-Amero and Bosley, 2005; Marriage et al.,

\footnotetext{
${ }^{1}$ Department of Nutrition and Food Sciences, Physiology and Toxicology, University of Navarra, Pamplona, Spain.

${ }^{2}$ Leia Foundation, C.D.T. Vitoria, Spain.

*The first two authors have contributed equally to this work.
} 
2003). The suitability of PBMCs for nutrigenomics studies is in part related to their active metabolism (Kussmann et al., 2006) and accessibility by a simple venipuncture (Liew et al., 2006; Marriage et al., 2003), which may also permit repeated time-series analysis of changes in gene expression in response to food-related interventions. Interestingly, a remarkable concordance $(>80 \%)$ of gene expression profiles between PBMC and different tissues has been demonstrated (Liew et al., 2006). Therefore, transcriptome analysis of peripheral blood is a promising approach for determining disease and treatment outcome (Debey et al., 2006). Based on these considerations, the aim of the present study was to investigate whether PBMC gene expression is a suitable model system to carry out nutrigenomics studies in human obesity. Moreover, we evaluated PBMC gene expression signatures to identify biomarkers that could predict individual differences in weight loss after a low-calorie diet (LCD).

\section{Subjects and Methods}

\section{Subjects}

The study was carried out in Caucasian obese men $(n=$ 9) carefully recruited to participate as volunteers (Table 1). Initial screening evaluations included a medical history, physical examination, and fasting blood profile to exclude subjects with clinical evidence of diabetes, hypertension, liver, renal or hematological disease, or other disorders that could interfere with the weight-loss process. Such features were tested by a specifically trained physician. Other exclusion criteria were weight change $\pm 3 \mathrm{~kg}$ within the 3 months before the start of the study, participation in another scientific study up to 1 month before, drug administration, pregnancy, surgical or drug-obesity treatment, or alcohol or drug abuse.

After a clear explanation of the study, all subjects gave their written informed consent to participate, which was previously approved by the Ethics Committee of the University of Navarra (54/2006), in agreement with the Helsinki Declaration.

\section{Study design}

The nutritional treatment involved an 8-week LCD, in which the energy restriction was set up at $-35 \%$ with respect to the total energy expenditure of each participant calculated by Harris-Benedict equation after applying the WHO's correction factor on physical activity [OMS (WHO), 2000]. The LCD was balanced for macronutrients (55\% of energy as carbohydrates, $15 \%$ as proteins, and $30 \%$ as fat). The menus were fixed following a dietary framework based on a food exchange system (Crujeiras et al., 2006, 2007; Tremblay et al., 1983). Each subject was provided with a detailed diet plan to follow for the 8 weeks and met with a dietician periodically. Weight loss was monitored weekly by a dietician, and the intake was controlled by 3-day weighted food records ( 2 weekdays and 1 weekend day). Foods records were performed during the week before the beginning of the intervention (week 0), and during the week before the end of the nutritional trial (week 8). These data provided information about baseline intake and the adherence to the prescribed diets. All subjects lost at least $5 \%$ of body weight as a result of the hypocaloric diet. At baseline (day 0) and at the end of the nutritional intervention (day 56), anthropometry was measured, and blood samples were collected with EDTA as anticoagulant to obtain the PBMC for gene expression analyses.

\section{Blood pressure and nutritinal status assessment}

Blood pressure was measured with a standard mercury sphygmomanometer (Minimus II, Riester, Germany) after the subject was quietly sitting for 5 min following OMS criteria. Plasma levels of glucose and total cholesterol were measured by specific colorimetric assays (Horiba ABX Diagnostics, Montpellier, France) using an automatized system (COBAS MIRA, Roche, Basel, Switzerland).

\section{Isolation of RNA from PBMC}

The PBMC were isolated by differential centrifugation using the PMN medium (Axis Shield PoC AS, Oslo, Norway). After PBS washing, the total RNA was extracted from PBMC by the Trizol reagent method (Invitrogen, Carlsbad, CA). Quantitation and purity of the RNA obtained were assessed by UV spectrophotometry (Multiskan Spectrum, Thermo Electron Corp., Finland). The RNA integrity was assesed using a 2100 Bioanalyzer instrument (Agilent Technologies, Palo Alto, CA). Additionaly, RNA quality was also checked on agarose gel electrophoresis.

\section{Synthesis and labeling of $c D N A$}

Fluorescently labeled cDNA was synthesized from $10 \mu \mathrm{g}$ of each total RNA sample. Anchored oligo(dT)20 and amino-allyl adducts (Sigma-Aldrich, St. Louis, MO) were used in the first strand cDNA synthesis reaction. The resulting amino modified cDNA was divided into two tubes, and each replicate was labeled using either $\mathrm{Cy} 3$ or $\mathrm{Cy} 5 \mathrm{flu}-$ orescent dyes (Amersham Biosciences, Piscataway, NJ), according to manufacturers protocols for appropriate dyeswap hybridizations.

\section{Microarray hybridization and image acquisition}

Samples were hybridized to the Human 1A Oligo Microarray Kit (V2) as described by the supplier (Agilent Technologies, Santa Clara, CA). Each single oligo microarray comprises over 22,575 probes and spans conserved exons across the targeted human full-length gene transcripts. Specifically, this array represents about 20,000 well-characterized, full-length human genes. This probe set is sourced from the Incyte Foundation Database, RefSeq, and GenBank databases.

RNA samples coming from PBMC that were taken before and after the nutritional intervention were differentially labeled and cohybridized on microarray slides. Appropriate dye-swap hybridizations (dye reversal) were also carried out to minimize potential biases arising from differences in the dyes. Microarrays were hybridized overnight at $60^{\circ} \mathrm{C}$ in hybridization chambers (Genetix, Boston, MA). After hybridizations slides were washed and dried prior to scanning.

Microarray images were obtained by scanning each slide in a Gene Pix 4100A scanner (Axon Instruments, Union City, CA). Image quantitation was performed using associated software GenePiX Pro 6.0 and median intensity background 


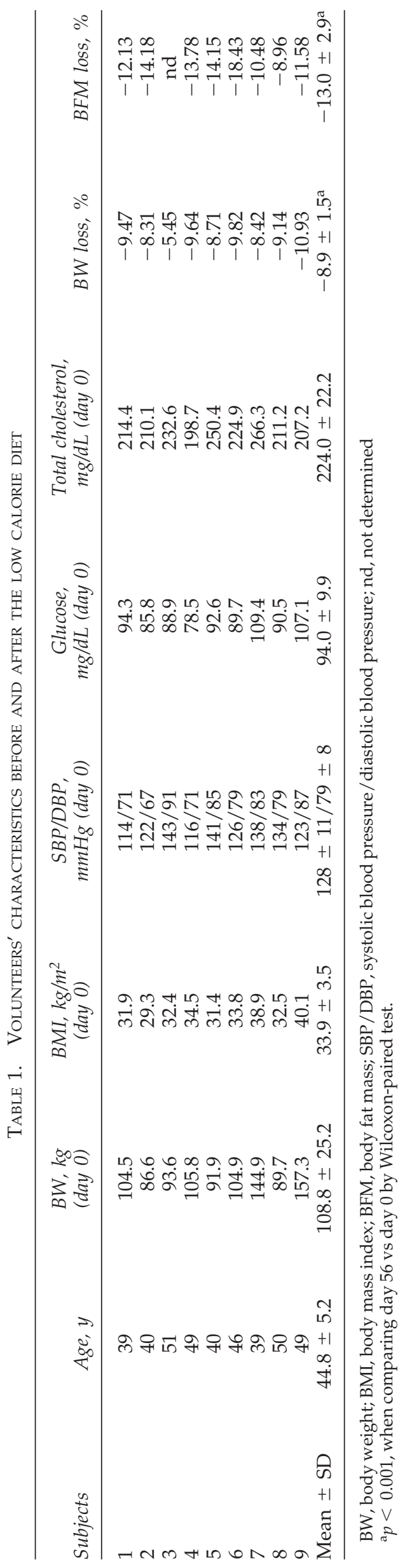


subtracted values for each spot were used in subsequent analysis.

\section{Normalization and data analysis}

Scanned microarray images were first examined for visible defects and then checked for the fitness of the gridding. When passed, the image file was analyzed to generate composite data files. From this point on, analyses were carried out using the GeneSpring GX software v 7.3.1 (Agilent Technologies).

To normalize data, intensity-dependent (LOWESS) normalization was used to eliminate dye-related artefacts. Once data were normalized, consecutive filtering steps were performed to remove noise derived from absent genes, background, and nonspecific hybridizations.

A Student's $t$-test was applied to select differentially expressed genes between both conditions (before and after nutritional intervention). Comparisons were performed for each gene, and genes with the most significant differential expression ( $p$-value cutoff $<0.05$ ) were returned. Additionally, statistically selected genes were assigned into specific Gene Ontology categories, as well as in KEGG associated pathways in order to extract maximum biological information. The GO ontologies provide a systematic language for the consistent description of attributes of genes and gene products in three key biological domains that are shared by all organisms: molecular function, biological process, and cellular component (The Gene Ontology Consortium, 2008).

\section{MIAME ArrayExpress}

The current microarray data have been curated and accepted in the ArrayExpress database. This is a public repository for microarray data, which is aimed at storing MIAME (Minimum Information About Microarray Experiments) compliant data in accordance with MGED (Microarray Gene Expression Data) recommendations. The ArrayExpress Data Warehouse stores gene-indexed expression profiles from a curated subset of experiments in the repository. Access to data concerning thus study may be found at ArrayExpress Web page (http://www.ebi.ac.uk/arrayexpress), with experiment accession number: E-MEXP-1055.

\section{Quantitative real-time PCR}

Quantitation of mRNA was performed using quantitative real-time polymerase chain reaction (qRT-PCR) to confirm microarray data. Extracted total RNA from all the subjects was purified with DNase treatment by means of DNA-free kit (Ambion, Austin TX) used as a template to generate firststrand cDNA synthesis using M-MLY reverse transcriptase as described by the manufacturer (Invitrogen). Quantitative real-time PCR was performed using an ABI PRISM 7000 HT Sequence Detection System as described by the provider (Applied Biosystems, Foster City, CA). Taqman probes for genes were supplied by Applied Biosystems and gene expression levels were normalized using $18 \mathrm{~S}$ rRNA as internal control, because this housekeeping gene does not change after the 8 weeks of low caloric diet, and it has been proved in previous studies with PBMC (Ghanim et al., 2004).

Eleven genes were selected for PCR quantificantion according to their association with the proinflammatory and/or oxidative stress processes. These genes were selected because of their importance in the respective metabolic pathways. Thus, regarding inflammation-related processes, all the genes selected (TANK, TNFAIP8L1, TRIAD3, NKRF, $T N I P 1$, and RIPK3) are related to $\mathrm{TNF} \alpha / \mathrm{NF}-\kappa \mathrm{B}$ signalling pathway, in addition to IL8. Regarding oxidative stress-related genes, some of them are involved in the mitochondrial function (NDUFS2, COX15, and ACAA2), whereas others are related to antioxidant defenses (MGST2).

\section{Statistical analysis}

The fold change in gene expression was calculated using the $2^{-\Delta \Delta C t}$ relative quantitation method, using the average of $C t$ values after subtraction with $C t$ value of $18 S$ from baseline (Livak and Schmittgen, 2001; Milagro et al., 2007) according to the manufacturer`s guidelines (Applied Biosystems). The nonparametric Wilcoxon-paired test was applied to detect differences before and after weight loss in anthropometric measurements, as well as the expression levels of selected genes. Data are reported as the mean \pm SD for anthropometric measurements and geometric mean (SEM as range) for qRT-PCR results. Correlation analysis was performed with Spearman rank order correlation. A $p$-value $\leq 0.05$ was considered as statistically significant and a $p$ value $\leq 0.1$ as a trend for significance. Statistical analysis was performed by SPSS 13.0 software (SPSS Inc. Chicago, IL) for Windows XP (Microsoft, Redmond, WA).

\section{Results}

Owing to the energy restriction, all volunteers lost body weight $(-8.9 \pm 1.5 \%)$, which was accompanied by a marked decrease in body mass index (Table 1). The microarray comparison between before and after the nutritional intervention resulted in 385 differentially expressed genes, with 158 genes overexpresed and 227 genes downregulated after the LCD treatment with respect to baseline before following the LCD. As shown in Figure 1, genes encoding factors involved in nucleotide, DNA, and chromatin metabolism, as well as in cellular biosynthetic and regulation of metabolic processes, including protein and lipid metabolic pathways, were mostly upregulated ( $p \leq 0.05$ ), whereas those related to signal transduction, cell communication, transport, immune response, and carbohydrate metabolism were mostly downregulated $(p \leq 0.05)$.

Gene ontology and pathway analysis (Table 2) showed that the biological functions associated with carbohydrate, lipid, and protein metabolism, oxidative phosphorylation, immune response, and coagulation were affected by the nutritional intervention. Moreover, after weight loss, other genes involved in relevant metabolic pathways, such as $S I R T 2, G H R L, R B P 2$, and SRF, were differentially expressed (Table 2).

After analyzing microarray data, 11 oxidative stress and inflammation-related genes were selected for qRT-PCR quantification. Thus, although some genes related to the $\mathrm{TNF} \alpha / \mathrm{NF}-\kappa \mathrm{B}$ signaling pathway did not change their expression, such as TANK, TNFAIP8L1, TRIAD3, and NKRF, others, such as TNIP1 and RIPK3, as well as IL8, significantly decreased after the LCD treatment (Table 3). Regarding oxidative stress related genes, NDUFS2 significantly decreased the expression levels in PBMC, while no changes in MGST2, 

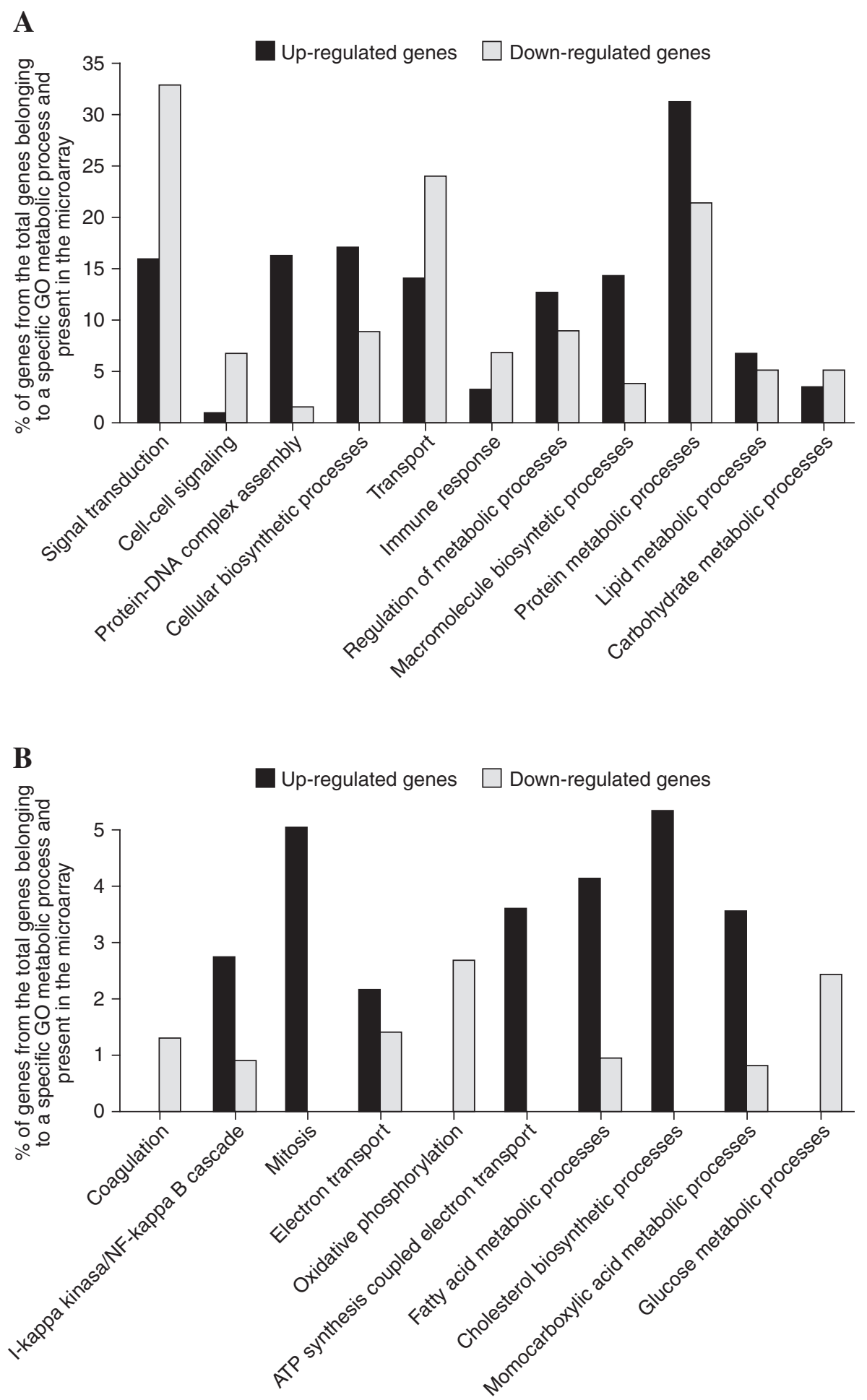

FIG. 1. Histograms showing some biological processes differentially regulated by weight loss in PBMC of obese subjects treated by an 8-week low-caloric diet. (A) Some metabolic processes from levels 4 and 5 of Gene Ontology, which are stated in the X-axis. (B) Other specific molecular functions belonging to levels 3 to 7 of Gene Ontology (GO), which are stated in the $\mathrm{X}$ axis. In the $\mathrm{Y}$-axis, the percentage of genes belonging to each biological process showed in the $\mathrm{X}$-axis that are downor upregulated by the caloric restriction treatment, is represented compared to the total number of genes of each biological process that are present in the microarray. 
TABle 2. SELECTED GENES AND PATHWAYS OF INTEREST CONCERNING CHANGES IN PBMC GENE EXPRESSION PROFILING LIST AFTER WEIGHT LOSS

\begin{tabular}{|c|c|c|c|}
\hline Pathways and Genes & Gene symbol & GenBank ID & Fold change \\
\hline \multicolumn{4}{|l|}{ Protein metabolism } \\
\hline Solute carrier family 7 & SLC7A4 & NM_004173 & $0.78 \pm 0.05$ \\
\hline Gamma-glutamyltransferase-like activity 1 & GGTLA1 & NM_004121 & $0.71 \pm 0.16$ \\
\hline Homogentisate 1,2-dioxygenase & HGD & NM_000187 & $0.89 \pm 0.05$ \\
\hline Acireductone dioxygenase 1 & MTCBP-1 & NM_018269 & $1.30 \pm 0.27$ \\
\hline Glutaminase 2 & GLS2 & NM_013267 & $1.31 \pm 0.34$ \\
\hline Nitrogen fixation 1 homolog & NFS1 & NM_021100 & $1.50 \pm 0.41$ \\
\hline \multicolumn{4}{|l|}{ Carbohydrate metabolism } \\
\hline ST6 beta-galactosamide alpha-2,6-sialyltranferase 2 & ST6GAL2 & NM_032528 & $0.58 \pm 0.18$ \\
\hline Alcohol dehydrogenase IB & ADH1B & NM_000668 & $0.73 \pm 0.19$ \\
\hline Ribose 5-phosphate isomerase A & RPIA & NM_144563 & $0.84 \pm 0.11$ \\
\hline Glycogenin 2 & GYG2 & NM_003918 & $0.77 \pm 0.19$ \\
\hline Insulin receptor substrate 2 & IRS2 & NM_003749 & $0.87 \pm 0.11$ \\
\hline Xylosyltransferase II & XYLT2 & NM_022167 & $1.11 \pm 0.05$ \\
\hline Hyaluronoglucosaminidase 1 & HYAL1 & NM_007312 & $1.21 \pm 0.16$ \\
\hline Fucosyltransferase 8 & FUT8 & NM_178154 & $1.28 \pm 0.24$ \\
\hline Lactate dehydrogenase D & LDHD & NM_153486 & $1.27 \pm 0.31$ \\
\hline \multicolumn{4}{|l|}{ Lipid metabolism } \\
\hline Apolipoprotein C-I & APOC1 & NM_001645 & $0.84 \pm 0.08$ \\
\hline Very low density lipoprotein receptor & VLDLR & NM_003383 & $0.88 \pm 0.06$ \\
\hline Acetyl-Coenzyme A acyltransferase 2 & ACAA2 & NM_006111 & $1.26 \pm 0.15$ \\
\hline Acyl-CoA synthetase long-chain family member 5 & ACSL5 & NM_203380 & $1.24 \pm 0.23$ \\
\hline Phospholipase A2, group XIIB & PLA2G12B & NM_032562 & $1.42 \pm 0.41$ \\
\hline Patatin-like phospholipase domain containing 3 & ADPN & NM_025225 & $0.66 \pm 0.21$ \\
\hline Gamma-glutamyltransferase-like activity 1 & GGTLA1 & NM_004121 & $0.71 \pm 0.16$ \\
\hline Pancreatic lipase-related protein 1 & PNLIPRP1 & NM_006229 & $0.75 \pm 0.18$ \\
\hline Apolipoprotein L, 1 & APOL1 & NM_145344 & $0.84 \pm 0.12$ \\
\hline 24-dehydrocholesterol reductase & DHCR24 & NM_014762 & $1.05 \pm 0.05$ \\
\hline Sphingosine kinase 1 & SPHK1 & NM_021972 & $1.27 \pm 0.28$ \\
\hline Fatty acid transport protein 4 & SLC27A4 & AF055899 & $0.98 \pm 0.61$ \\
\hline Microsomal glutahione S-transferase 2 & MGST2 & NM_002413 & $1.28 \pm 0.32$ \\
\hline \multicolumn{4}{|l|}{ Oxidative Phosphorilation } \\
\hline ATPase, $\mathrm{H}+$ transporting, lysosomal V0 subunit a4 & ATP6V0A4 & NM_020632 & $0.74 \pm 0.10$ \\
\hline Cytochrome $c$ oxidase assembly protein & COX15 & NM_078470 & $0.68 \pm 0.21$ \\
\hline NADH-coenzyme $\mathrm{Q}$ reductase & NDUFS2 & NM_004550 & $0.77 \pm 0.18$ \\
\hline Cytochrome b-561 & CYB561 & NM_001017916 & $1.15 \pm 0.12$ \\
\hline \multicolumn{4}{|l|}{ Immune Response } \\
\hline T-cell activation antigen CD26 & DPP4 & NM_001935 & $0.79 \pm 0.10$ \\
\hline Tumor necrosis factor related protein 4 & C1QTNF4 & NM_031909 & $0.88 \pm 0.04$ \\
\hline TNFAIP3 interacting protein 1 & TNIP1 & NM_006058 & $0.92 \pm 0.06$ \\
\hline Tumor necrosis factor (ligand) superfamily, member 8 & TNFSF8 & NM_001244 & $0.86 \pm 0.12$ \\
\hline T-cell surface glycoprotein CD8 beta chain & CD8B1 & NM_172099 & $1.09 \pm 0.10$ \\
\hline Rho-related GTP-binding protein & $\mathrm{RHOH}$ & NM_004310 & $1.14 \pm 0.13$ \\
\hline Tumor necrosis factor, alpha-induced protein 8-like1 & TNFAIP8L1 & NM_152362 & $1.33 \pm 0.37$ \\
\hline Bloom syndrome protein & BLM & NM_000057 & $1.54 \pm 0.72$ \\
\hline Interferon, alpha 16 & IFNA16 & NM_002173 & $1.85 \pm 0.85$ \\
\hline Interleukin-1 receptor-associated kinase 4 & IRAK4 & NM_016123 & $0.68 \pm 0.16$ \\
\hline Coagulation factor III (thromboplastin, tissue factor) & F3 & NM_001993 & $0.71 \pm 0.13$ \\
\hline Prostate associated gene 1 & PAGE1 & NM_003785 & $0.67 \pm 0.18$ \\
\hline Killer cell lectin-like receptor subfamily A & KLRA1 & NM_006611 & $0.68 \pm 0.20$ \\
\hline $\mathrm{T}$-cell receptor $\mathrm{T} 3$ gamma chain & CD3G & NM_000073 & $0.78 \pm 0.15$ \\
\hline B-lymphocyte antigen CD19 & CD19 & NM_001770 & $0.77 \pm 0.16$ \\
\hline ATP-binding cassette transporter & TAP1 & NM_000593 & $0.84 \pm 0.09$ \\
\hline CD24 molecule & CD24 & NM_013230 & $0.88 \pm 0.07$ \\
\hline Adenosine deaminase, RNA-specific & ADAR & NM_001111 & $0.82 \pm 0.15$ \\
\hline Interferon, alpha-inducible protein 6 & G1P3 & NM_022873 & $1.12 \pm 0.11$ \\
\hline Oral-facial-digital syndrome 1 & OFD1 & NM_003611 & $1.23 \pm 0.24$ \\
\hline Microsomal glutahione S-transferase 2 & MGST2 & NM_002413 & $1.28 \pm 0.32$ \\
\hline Bradykinin receptor B1 & BDKRB1 & NM_000710 & $1.52 \pm 0.64$ \\
\hline Interleukin 8 & IL8 & NM_000584 & $1.32 \pm 1.07^{\mathrm{a}}$ \\
\hline
\end{tabular}


TABlE 2. SELECTED GENES AND PATHWAYS OF INTEREST CONCERNING CHANGES IN PBMC GENE EXPRESSION PROFILING LIST AFTER WEIGHT LOSS (CONT'D)

\begin{tabular}{|c|c|c|c|}
\hline Pathways and Genes & Gene symbol & GenBank ID & Fold change \\
\hline \multicolumn{4}{|l|}{ NF-kappa-B-responsive genes } \\
\hline TRIAD 3 protein & TRIAD3 & NM_207111 & $0.77 \pm 0.10$ \\
\hline Receptor-interacting serine-threonine kinase 3 & RIPK3 & NM_006871 & $0.68 \pm 0.22$ \\
\hline NF-kappaB repression factor & NKRF & NM_017544 & $0.84 \pm 0.10$ \\
\hline TNFAIP3 interacting protein 1 & TNIP1 & NM_006058 & $0.92 \pm 0.06$ \\
\hline $\begin{array}{l}\text { TRAF (tumor necrosis factor receptor-associated factor) } \\
\text { family member-associated NF-kappaB activator }\end{array}$ & TANK & NM_004180 & $1.09 \pm 0.08$ \\
\hline \multicolumn{4}{|l|}{ Coagulation } \\
\hline Coagulation factor III (thromboplastin, tissue factor) & F3 & NM_001993 & $0.71 \pm 0.13$ \\
\hline Vitamin K-dependent gamma-carboxylase & GGCX & NM_000821 & $0.68 \pm 0.22$ \\
\hline \multicolumn{4}{|l|}{ Other Genes } \\
\hline Ghrelin & GHRL & NM_016362 & $0.79 \pm 0.15$ \\
\hline Sirtuin & SIRT2 & NM_012237 & $1.18 \pm 0.11$ \\
\hline $\begin{array}{l}\text { c-Fos serum response element-binding transcription } \\
\text { factor }\end{array}$ & SRF & NM_003131 & $1.37 \pm 0.37$ \\
\hline Retinol binding protein 2 & RBP2 & NM_004164 & $1.51 \pm 0.69$ \\
\hline
\end{tabular}

All the genes in this list were significantly up- or down-regulated $(p<0.05)$ when analyzing the microarray by Student's t-test except for those marked with (a).

COX15, and ACAA2 were found after the weight loss induced by a LCD (Table 3).

A consistent positive correlation was detected among mRNA levels of some of the genes studied (Table 4). Thus, RIPK3 was highly associated with TANK, TNIP1, and TRIAD3, all of them in the TNF $\alpha / \mathrm{NF}-\kappa \mathrm{B}$ pathway. TNIP was also related to other genes of this pathway, such as TANK and TRIAD3, while TNFAIP8L1 was correlated with $N K R F$ and $T A N K$, suggesting that these genes share the same regulatory pathway.

On the other hand, the oxidative stress-related genes were also associated each other and with the inflammation-related genes (Table 4). Finally, significant correlations were found between body weight and mRNA expression of TNIP $(r=$ $0.62 ; p=0.006)$ and TANK $(r=0.53 ; p=0.023)$, and NDUFS2 tended to be correlated $(r=0.40 ; p=0.098)$, before and after caloric restriction treatment $(n=18)$. While, TRIAD3 mRNA levels $(r=74 ; p=0.037)$ after the intervention were associated with body weight at this point, together a trend for a correlation in the ACAA2 transcripts $(r=0.64 ; p=$ 0.066). Interestingly, a lower IL8 gene expression after LCD was associated with higher fat mass decrease (Fig. 2).

\section{Discussion}

The impact of nutrition on gene expression is being explored in the obesity domain because nutrigenomics approach could be applied to personalize nutrition (Kaput, 2008; Ronteltap et al., 2008). In this context, technologies involved in DNA microarrays make it possible to assess the effect of

TABLE 3. EXPRESSION CHANGES FROM SELECTED GENES IN PBMC ASSESSED BY QRT-PCR AFTER WEIGHT LOSS INDUCED BY A LCD IN OBESE VOLUNTEERS.

\begin{tabular}{llll}
\hline Gene symbol & GenBank ID & qRT-PCR & p-value \\
\hline Inflammation-related genes & & & \\
RIPK3 & NM_006871 & $0.72(0.62-0.85)$ & $\mathbf{0 . 0 8 6}$ \\
TNIP1 & NM_006058 & $0.70(0.63-0.78)$ & 0.021 \\
NKRF & NM_017544 & $0.90(0.74-1.09)$ & 0.314 \\
TANK & NM_004180 & $0.85(0.71-1.01)$ & $0.85(0.72-0.99)$ \\
TRIAD3 & NM_207111 & $0.87(0.70-1.09)$ & 0.263 \\
TNFAIP8L1 & NM_152362 & $0.46(0.29-0.73)$ & 0.314 \\
IL8 & NM_000584 & & $\mathbf{0 . 0 6 6}$ \\
& & $1.03(0.78-1.20)$ & \\
Oxidative stress-related genes & & $0.91(0.73-1.14)$ & 0.678 \\
ACAA2 & NM_006111 & $0.71(0.63-0.80)$ & 0.678 \\
COX15 & NM_078470 & $1.19(1.02-1.39)$ \\
NDUFS2 & NM_004550 & $\mathbf{0 . 0 2 1}$ \\
MGST2 & NM_002413 & 0.374 \\
\hline
\end{tabular}

mRNA levels were normalized to $18 \mathrm{~S}$. Fold changes were evaluated using the $2^{-\Delta \Delta \mathrm{Ct}}$ method of relative quantification above the expression levels of before low calorie treatment state (set at unity). Data are reported as geometric mean (S.E.M as a range). 
TABle 4. SPEARMAN RANK ORDER CORRELATION ANALYSIS BETWEEN THE EXPRESSION OF THE EVALUATED GENES

\begin{tabular}{|c|c|c|c|c|c|c|c|c|c|c|}
\hline & \multicolumn{6}{|c|}{ Inflammation-related genes } & \multicolumn{4}{|c|}{ Oxidative stress-related genes } \\
\hline & TNIP1 & $N K R F$ & TANK & TRIAD3 & TNFAIP8L1 & IL8 & $A C A A 2$ & COX15 & NDUFS2 & MGST2 \\
\hline RIPK3 & $0.68^{c}$ & 0.38 & $0.83^{\mathrm{b}}$ & $0.71^{\mathrm{c}}$ & 0.55 & 0.43 & $0.80^{c}$ & $0.69^{c}$ & $0.80^{c}$ & $0.79^{c}$ \\
\hline TNIP1 & & 0.60 & $0.82^{\mathrm{b}}$ & $0.76^{\mathrm{c}}$ & 0.58 & 0.30 & $0.73^{c}$ & 0.38 & 0.60 & 0.60 \\
\hline NKRF & & & 0.32 & $0.83^{c}$ & $0.93^{a}$ & 0.33 & $0.72^{c}$ & 0.56 & 0.27 & 0.18 \\
\hline TANK & & & & $0.79^{c}$ & 0.48 & 0.17 & $0.73^{c}$ & 0.59 & $0.93^{\mathrm{b}}$ & $0.88^{b}$ \\
\hline TRIAD3 & & & & & $0.90^{\mathrm{b}}$ & 0.48 & $0.90^{\mathrm{b}}$ & $0.76^{\mathrm{c}}$ & $0.68^{c}$ & 0.50 \\
\hline TNFAIP8L1 & & & & & 0.28 & $0.85^{\mathrm{b}}$ & $0.74^{\mathrm{c}}$ & 0.50 & 0.35 & \\
\hline IL8 & & & & & & & 0.48 & 0.33 & 0.033 & -0.08 \\
\hline ACAA2 & & & & & & & & $0.83 \ddagger$ & $0.68^{c}$ & 0.53 \\
\hline COX15 & & & & & & & & & $0.73^{c}$ & 0.59 \\
\hline NDUFS2 & & & & & & & & & & $0.93^{a}$ \\
\hline
\end{tabular}

Data showed the Spearman correlation coefficient $(r)$.

${ }^{\mathrm{a}} p<0.001 ;{ }^{\mathrm{b}} p<0.01 ; \mathrm{c} p<0.05$.

a specific diet or nutrient on the expression of a large number of genes (Afman and Muller, 2006; Kussmann et al., 2006; Puskas et al., 2006). Recent examples of this approach show differential gene expression profiling during nutritional intervention both in animal models (Campion et al., 2006; Lopez et al., 2003) or in human biopsies of adipose tissue (Baranova et al., 2005; Clement et al., 2004; Viguerie et al., 2005a). However, few studies have been performed in humans, where an important barrier to identify molecular biomarkers is the inaccessibility to tissue samples (Muller and Kersten, 2003). It would be useful to find a noninvasive source of RNA to explore the role of gene expression in the context of human diet intervention studies. Thus, the gene expression differences in normal individuals has suggested the power of the gene expression in PBMC to study the variation in populations that may account for differences in disease incidence and treatment response (Radich et al., 2004). Accordingly, some authors have recently studied the responses to dietary exposure by analyzing the gene expression profile in blood cells, suggesting that this kind of sample could be applied to perform nutrigenomics studies (van Erk et al., 2006). Moreover, a previous study showed 35 common genes downregulated both in adipose tissue and PBMC from controls compared to obese (García-Amigot et al., 2005). In this sense, the current experimental study has specifically utilized PBMC samples, collected by simple blood extraction,

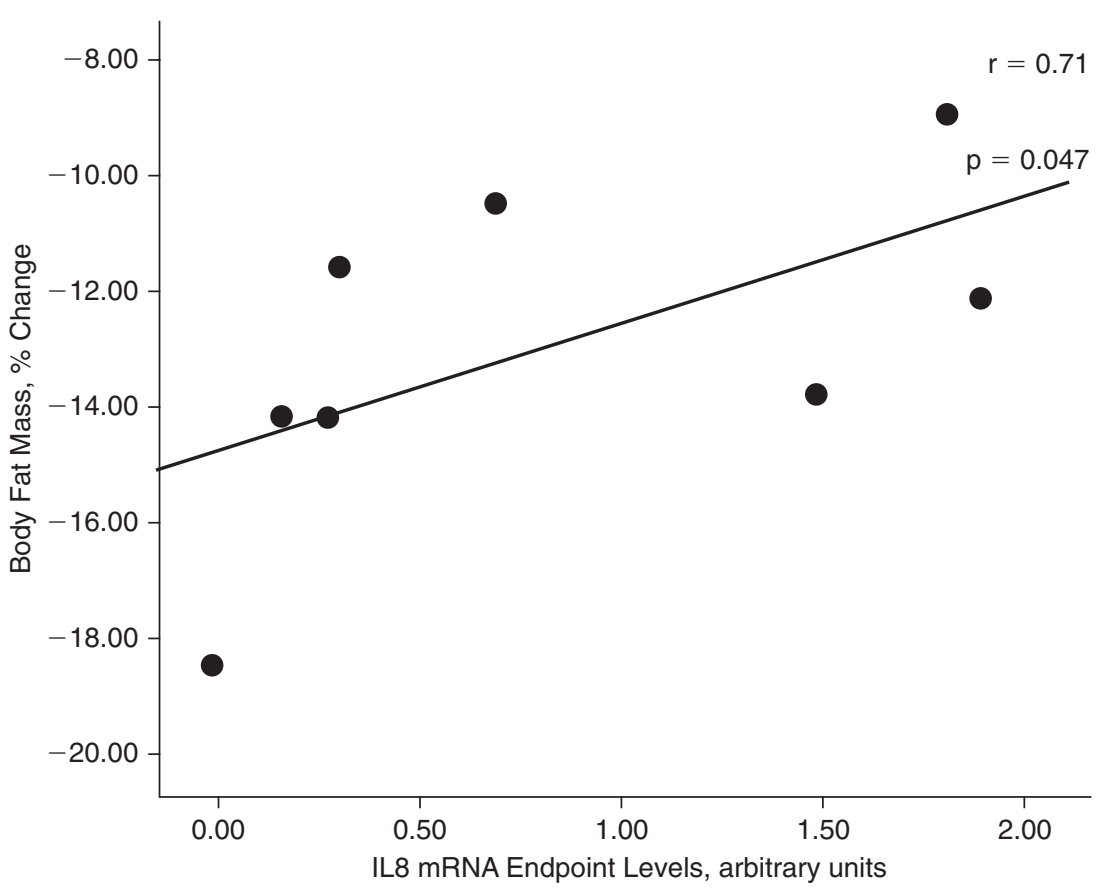

FIG. 2. Correlation between IL8 gene expression in blood peripheral mononuclear cells after nutritional intervention and changes in body fat mass after weight loss. Data show that lower IL8 transcripts were related to higher decrease in body fat mass induced by LCD. 
instead of fat biopsies, to perform nutrigenomics studies in obese subjects, and with the additional advantage that this sample type could be a source of information about the oxidative stress and inflammatory status, which are both increased in obesity and its complications (Vincent and Taylor, 2006).

In the context of obesity treatment, dietary interventions such as caloric restriction diets remain the most efficient therapeutic approach to promote weight loss in obese subjects (Abete et al., 2006). Moreover, hypocaloric diets have been proposed to empower the oxidative stress improvement related to weight loss through a reduction in lipid peroxidation (Crujeiras et al., 2006, 2007). Global gene expression profiling in PBMC, performed in the current work by using DNA microarrays, revealed that a 8 -week LCD devised to lose weight is able to modulate a wide variety of biological processes, such as macronutrient metabolism, coagulation, immune response, and oxidative phosphorylation. The first step in this study shows that several PBMC biological processes could be regulated in the same direction that in adipose tissue after nutritional intervention in obesity (Viguerie et al., 2005a, 2005b). For example, the genes related to signal transduction, cell-cell signaling, and immune response, together with genes associated with insulin sensitivity such as TNF- $\alpha / N F-\kappa$ B signal cascade pathway were mostly downregulated by caloric restriction. Conversely, protein-DNA assembly complex and biosynthetic and metabolic regulation processes were upregulated (Clement et al., 2004; Higami et al., 2004; Viguerie et al., 2005a, 2005b). In addition, most of changes in gene expression found in this study, were between of the range (overexpressed: 1.2-2.9; downregulated: $0.8-0.4)$ previously reported in adipose tissue after 28 day very LCD (Clement et al., 2004).

Some genes also modulated by the nutritional intervention, such as SIRT2 (sirtuin), GHRL (ghrelin), and RPB2 (retinol binding protein 2) are, as far as we know, described in PBMC for the first time.

Further validation by qRT-PCR confirmed that some key genes involved in the TNF- $\alpha$ and the nuclear factor NF- $\kappa \mathrm{B}$ signal cascade pathway, such as RIPK3 (receptor-interacting serine-threonine kinase 3 ) and TNIP1 (TNF- $\alpha$-induced protein 3 interacting protein 1) were downregulated by a LCD. RIPK3 is a family member of the receptor-interacting proteins implicated in activation of NF- $\kappa \mathrm{B}$ and induction of apoptosis (Yang et al., 2005) and TNIP1, also known as Naf1, can inhibit NF- $\kappa$ B-dependent gene expression (Gallagher et al., 2003). These findings are in agreement with reports from human adipose tissue, which showed an improvement in the inflammatory profile induced by caloric restriction (Clement et al., 2004).

Also, other important genes related to oxidative phosphorylation, the main source of free radicals (Finkel and Holbrook, 2000), such as NDUFS2 (NADH-coenzyme Q reductase), were downregulated by the nutritional intervention, suggesting a possible mitochondrial adaptation that could trigger a decrease in reactive oxygen species production, as has been shown after caloric restriction in rat liver studies (Ayala et al., 2007) and human muscle biopsies (Civitarese et al., 2007).

Therefore, our results suggest a beneficial effect induced by weight loss or negative energy balance on the TNF- $\alpha$ /NF$\kappa \mathrm{B}$ signaling cascade and in oxidative stress, which are both associated with obesity and insulin resistance (Dandona et al., 2005). Reinforcing these findings, the body weight appears to regulate the expression of some genes, such as TNIP, TANK, TRIAD3, ACAA2, and NDUFS2, as shown by the correlation analyses, suggesting that these genes could be good markers of body weight in PBMC, despite the fact that a correlation between the gene expression and the diet-induced changes in the body weight was not detected. However, it should not be discarded that not only weight loss but also the negative energy balance could have influenced in the regulation of these genes. Caloric restriction by itself has been suggested to regulate adipose tissue gene expression independently of the fat mass loss (Viguerie et al., 2005a).

Interestingly, the expression of IL8 (Interleukin 8), a proinflammatory cytokine regulated by reactive oxygen intermediates (DeForge et al., 1993; Lekstrom-Himes et al., 2005), tended to be downregulated in PBMC after weight loss induced by caloric restriction. This decrease in IL8 expression was closely associated to the LCD-induced reduction in body fat mass, suggesting that it could be a good indicator of variations in body fat percentage. This finding supports previous work indicating a upregulation of IL8 gene expression in preadipocytes of obese subjects (Nair et al., 2005), as well as studies that show a decrease in the adipose tissue IL8 secretion in humans treated following a hypocaloric diets (Arvidsson et al., 2004).

Summing up, the current study demonstrates the applicability of circulating mononuclear cells in the search of transcriptional biomarkers in the context of body weight regulation and nutritional treatments. Moreover, we report for the first time, the differential expression profile of oxidative stress and inflammation related genes in these cells under a model of weight loss induced by an LCD, which is of particular relevance given the current view of obesity as a lowdegree proinflammatory disease (Moreno-Aliaga et al., 2005; Vincent and Taylor, 2006). In addition, the IL8 gene expression in PBMC could be proposed as a possible biomarker for obesity treatment outcome, given the relationship found between the decrease in body fat mass and IL 8 transcripts. However, this finding should be corroborated in a future studies.

Therefore, gene expression in PBMC could be used for diagnosis and development of therapeutic strategies in obesity, and could be applied in a more personalized nutritional approach based on nutrigenomics studies.

\section{Acknowledgments}

We wish to thank our physician Blanca E Martínez de Morentin, our nurse Salomé Pérez, our dietician María Hernandez, and our technicians Verónica Ciaurriz and Ana Lorente for excellent clinical and technical assistance. Also, thanks are given to Friends Association of University of Navarra and Caixanova, as well as to Dpt. of Education, Universities and Research of the Basque Government that support A.B. Crujeiras and E. Goyenechea, respectively, with a grant fellowship. This work has been supported by Linea Especial about Nutrition, Obesity and Health (University of Navarra LE/97).

\section{Author Disclosure Statement}

The author declares there are no conflicts of interest. 


\section{References}

Abete, I., Parra, M., Zulet, M., and Martinez, J.A. (2006). Different dietary strategies for weight loss in obesity: role of energy and macronutrient content. Nutr Res Rev 19, 1-19.

Abu-Amero, K.K., and Bosley, T.M. (2005). Detection of mitochondrial respiratory dysfunction in circulating lymphocytes using resazurin. Arch Pathol Lab Med 129, 1295-1298.

Achiron, A., and Gurevich, M. (2006). Peripheral blood gene expression signature mirrors central nervous system disease: the model of multiple sclerosis. Autoimmun Rev 5, 517-522.

Afman, L., and Muller, M. (2006). Nutrigenomics: from molecular nutrition to prevention of disease. J Am Diet Assoc 106, 569-576.

Arvidsson, E., Viguerie, N., Andersson, I., Verdich, C., Langin, D., and Arner, P. (2004). Effects of different hypocaloric diets on protein secretion from adipose tissue of obese women. Diabetes 53, 1966-1971.

Ayala, V., Naudi, A., Sanz, A., Caro, P., Portero-Otin, M., Barja, G., and Pamplona, R. (2007). Dietary protein restriction decreases oxidative protein damage, peroxidizability index, and mitochondrial complex I content in rat liver. J Gerontol A Biol Sci Med Sci 62, 352-360.

Baranova, A., Collantes, R., Gowder, S. J., Elariny, H., Schlauch, K., Younoszai, A., et al. (2005). Obesity-related differential gene expression in the visceral adipose tissue. Obes Surg 15, 758-765.

Campion, J., Milagro, F. I., Fernandez, D., and Martinez, J. A. (2006). Diferential gene expression and adiposity reduction induced by ascorbic acid supplementation in a cafeteria model of obesity. J Physiol Biochem 62, 71-80.

Chiappini, F., Barrier, A., Saffroy, R., Domart, M. C., Dagues, N., Azoulay, D., et al. (2006). Exploration of global gene expression in human liver steatosis by high-density oligonucleotide microarray. Lab Invest 86, 154-165.

Civitarese, A.E., Carling, S., Heilbronn, L.K., Hulver, M.H., Ukropcova, B., Deutsch, W.A., et al. (2007). Calorie restriction increases muscle mitochondrial biogenesis in healthy humans. PLoS Med 4, e76.

Clement, K., Viguerie, N., Poitou, C., Carette, C., Pelloux, V., Curat, C. A., et al. (2004). Weight loss regulates inflammation-related genes in white adipose tissue of obese subjects. FASEB J 18, 1657-1669.

Crujeiras, A.B., Parra, M.D., Rodriguez, M.C., Martinez de Morentin, B.E., and Martinez, J.A. (2006). A role for fruit content in energy-restricted diets in improving antioxidant status in obese women during weight loss. Nutrition 22, 593-599.

Crujeiras, A.B., Parra, D., Abete, I., and Martinez, J. A. (2007). A hypocaloric diet enriched in legumes specifically mitigates lipid peroxidation in obese subjects. Free Radic Res 41, 498-506.

Dandona, P., Aljada, A., Chaudhuri, A., Mohanty, P., and Garg, R. (2005). Metabolic syndrome: a comprehensive perspective based on interactions between obesity, diabetes, and inflammation. Circulation 111, 1448-1454.

Debey, S., Zander, T., Brors, B., Popov, A., Eils, R., and Schultze, J.L. (2006). A highly standardized, robust, and cost-effective method for genome-wide transcriptome analysis of peripheral blood applicable to large-scale clinical trials. Genomics 87, 653-664.

DeForge, L.E., Preston, A.M., Takeuchi, E., Kenney, J., Boxer, L.A. and Remick, D.G. (1993). Regulation of interleukin 8 gene expression by oxidant stress. J Biol Chem 268, 25568-25576.

DePrimo, S.E., Wong, L.M., Khatry, D.B., Nicholas, S.L., Manning, W.C., Smolich, B.D., et al. (2003). Expression profiling of blood samples from an SU5416 Phase III metastatic colorectal cancer clinical trial: a novel strategy for biomarker identification. BMC Cancer 3, 3.

Eady, J.J., Wortley, G.M., Wormstone, Y.M., Hughes, J.C., Astley, S.B., Foxall, R.J., et al. (2005). Variation in gene expression profiles of peripheral blood mononuclear cells from healthy volunteers. Physiol Genomics 22, 402-411.

Finkel, T., and Holbrook, N.J. (2000). Oxidants, oxidative stress and the biology of ageing. Nature 408, 239-247.

Gallagher, J., Howlin, J., McCarthy, C., Murphy, E.P., Bresnihan, B., FitzGerald, O., et al. (2003). Identification of Naf1/ABIN-1 among TNF-alpha-induced expressed genes in human synoviocytes using oligonucleotide microarrays. FEBS Lett 551, 8-12.

García-Amigot, F.L.O., Marti, A, Moreno-Aliaga, M.J., Bandrés, E., García-Foncillas, J., and Martínez, J.A. (2005). Gene expression pattern of obese and control individuals in adipose tissue and peripheral blood mononuclear cells. In Trends in Obesity Research. P.R. Ling, ed., Nova Science, NY, pp. 67-84. Ghanim, H., Aljada, A., Hofmeyer, D., Syed, T., Mohanty, P., and Dandona, P. (2004). Circulating mononuclear cells in the obese are in a proinflammatory state. Circulation 110, 1564-1571.

Heidecker, B., and Hare, J.M. (2007). The use of transcriptomic biomarkers for personalized medicine. Heart Fail Rev, 12, $1-11$.

Hernandez-Morante, J.J., Milagro, F.I., Lujan, J.A., Martinez, J.A., Zamora, S, and Garaulet, M. (2008). Insulin effect on adipose tissue adiponectin expression is regulated by the insulin resistance status of the patients. Clin Endocrinol (Oxf), in press.

Higami, Y., Pugh, T.D., Page, G.P., Allison, D.B., Prolla, T.A., and Weindruch, R. (2004). Adipose tissue energy metabolism: altered gene expression profile of mice subjected to long-term caloric restriction. FASEB J 18, 415-417.

Horwitz, P.A., Tsai, E.J., Putt, M.E., Gilmore, J.M., Lepore, J.J., Parmacek, M.S., et al. (2004). Detection of cardiac allograft rejection and response to immunosuppressive therapy with peripheral blood gene expression. Circulation 110, 3815-3821.

Kaput, J. (2008). Nutrigenomics research for personalized nutrition and medicine. Curr Opin Biotechnol 19, 110-120.

Kussmann, M., Raymond, F., and Affolter, M. (2006). OMICSdriven biomarker discovery in nutrition and health. J Biotechnol 124, 758-787.

Lekstrom-Himes, J.A., Kuhns, D.B., Alvord, W.G., and Gallin, J.I. (2005). Inhibition of human neutrophil IL-8 production by hydrogen peroxide and dysregulation in chronic granulomatous disease. J Immunol 174, 411-417.

Liew, C.C., Ma, J., Tang, H.C., Zheng, R., and Dempsey, A.A. (2006). The peripheral blood transcriptome dynamically reflects system wide biology: a potential diagnostic tool. J Lab Clin Med 147, 126-132.

Livak, K.J., and Schmittgen, T.D. (2001). Analysis of relative gene expression data using real-time quantitative PCR and the 2(Delta Delta C(T)) Method. Methods 25, 402-408.

Lopez, I.P., Marti, A., Milagro, F.I., Zulet, M.A., Moreno-Aliaga, M.J., Martinez, J.A., and De Miguel, C. (2003). DNA microarray analysis of genes differentially expressed in diet-induced (cafeteria) obese rats. Obes Res 11, 188-194.

Maes, O.C., Xu, S., Yu, B., Chertkow, H.M., Wang, E., and Schipper, H.M. (2007). Transcriptional profiling of Alzheimer blood mononuclear cells by microarray. Neurobiol Aging 28, 1795-1809.

Mariman, E.C. (2006). Nutrigenomics and nutrigenetics: the "omics" revolution in nutritional science. Biotechnol Appl Biochem 44, 119-128.

Marrades, M.P., Milagro, F.I., Martinez, J.A., and MorenoAliaga, M.J. (2006). Differential expression of aquaporin 7 in 
adipose tissue of lean and obese high fat consumers. Biochem Biophys Res Commun 339, 785-789.

Marriage, B.J., Clandinin, M.T., MacDonald, I.M., and Glerum, D.M. (2003). The use of lymphocytes to screen for oxidative phosphorylation disorders. Anal Biochem 313, 137-144.

Milagro, F.I., Campion, J., and Martinez, J.A. (2007). 11-beta Hydroxysteroid dehydrogenase type 2 expression in white adipose tissue is strongly correlated with adiposity. J Steroid Biochem Mol Biol 104, 81-84.

Moreno-Aliaga, M.J., Campion, J., Milagro, F., Berjín, A., and Martínez, J.A. (2005). Adiposity and proinflammatory state: the chicken or the egg. Adipocytes 1, 1-16.

Moreno-Aliaga, M.J., Marti, A., Garcia-Foncillas, J., and Martinez, J.A. (2001). DNA hybridization arrays: a powerful technology for nutritional and obesity research. Br J Nutr 86, 119-122.

Muller, M. and Kersten, S. (2003). Nutrigenomics: goals and strategies. Nat Rev Genet 4, 315-322.

Nair, S., Lee, Y.H., Rousseau, E., Cam, M., Tataranni, P.A., Baier, L.J., et al. (2005). Increased expression of inflammation-related genes in cultured preadipocytes/stromal vascular cells from obese compared with non-obese Pima Indians. Diabetologia 48, 1784-1788.

OMS (WHO). (2000). Obesity: preventing and managing the global epidemic. Report of a WHO consulation. Word Health Organ Tech Rep Ser 894, 1-253.

Patalay, M., Lofgren, I.E., Freake, H.C., Koo, S.I., and Fernandez, M.L. (2005). The lowering of plasma lipids following a weight reduction program is related to increased expression of the LDL receptor and lipoprotein lipase. J Nutr 135, 735-739.

Puskas, L.G., Menesi, D., Feher, L.Z., and Kitajka, K. (2006). High-throughput functional genomic methods to analyze the effects of dietary lipids. Curr Pharm Biotechnol 7, 525-529.

Radich, J.P., Mao, M., Stepaniants, S., Biery, M., Castle, J., Ward, T., Schimmack, G., Kobayashi, S., Carleton, M., et al. (2004). Individual-specific variation of gene expression in peripheral blood leukocytes. Genomics 83, 980-988.

Ronteltap, A., van Trijp, J.C., and Renes, R.J. (2008). Consumer acceptance of nutrigenomics-based personalised nutrition. $\mathrm{Br}$ J Nutr 15, 1-13.

Sun, G. (2007). Application of DNA microarrays in the study of human obesity and type 2 diabetes. Omics 11, 25-40.
The Gene Ontology Consortium (2008). The Gene Ontology project in 2008. Nucleic Acids Res 36, D440-D444.

Tremblay, A., Sevigny, J., Leblanc, C., and Bouchard, C (1983). The reproducibility or a three-day dietary record. Nutr Res 3, 819-830.

Twine, N.C., Stover, J.A., Marshall, B., Dukart, G., Hidalgo, M., Stadler, W., et al. (2003). Disease-associated expression profiles in peripheral blood mononuclear cells from patients with advanced renal cell carcinoma. Cancer Res 63, 6069-6075.

Vakili, S., and Caudill, M. A. (2007). Personalized nutrition: nutritional genomics as a potential tool for targeted medical nutrition therapy. Nutr Rev 65, 301-315.

van Erk, M.J., Blom, W.A., van Ommen, B., and Hendriks, H.F. (2006). High-protein and high-carbohydrate breakfasts differentially change the transcriptome of human blood cells. Am J Clin Nutr 84, 1233-1241.

Viguerie, N., Poitou, C., Cancello, R., Stich, V., Clement, K., and Langin, D. (2005a). Transcriptomics applied to obesity and caloric restriction. Biochimie 87, 117-123.

Viguerie, N., Vidal, H., Arner, P., Holst, C., Verdich, C., Avizou, $\mathrm{S}$., et al. (2005b). Adipose tissue gene expression in obese subjects during low-fat and high-fat hypocaloric diets. Diabetologia 48, 123-131.

Vincent, H.K., and Taylor, A.G. (2006). Biomarkers and potential mechanisms of obesity-induced oxidant stress in humans. Int J Obes (Lond) 30, 400-418.

Yang, Y., Hu, W., Feng, S., Ma, J., and Wu, M. (2005). RIP3 beta and RIP3 gamma, two novel splice variants of receptor-interacting protein 3 (RIP3), downregulate RIP3-induced apoptosis. Biochem Biophys Res Commun 332, 181-187.

Address reprint requests to: Prof. J. Alfredo Martínez Department of Nutrition and Food Sciences, Physiology and Toxicology

University of Navarra C/ Irunlarrea 1 31008 Pamplona, Spain

E-mail: jalfmtz@unav.es 